\title{
Polyurethane/Polyhydroxyurethane Hybrid Polymers and Their Applications as Adhesive Bonding Agents
}

\author{
Emily K. Leitsch, ${ }^{\mathrm{a}}$ William H. Heath, ${ }^{\mathrm{b}}$ and John M. Torkelson ${ }^{\mathrm{a}, \mathrm{c} *}$ \\ ${ }^{a}$ Dept. of Chemical and Biological Eng., Northwestern University, Evanston, IL 60208 USA \\ ${ }^{b}$ Dept. of Polyurethanes R\&D, The Dow Chemical Company, 2301 N. Brazoport Blvd., B-1608, \\ Freeport, TX 77541 USA \\ ${ }^{c}$ Dept. of Materials Science and Eng., Northwestern University, Evanston, IL 60208 USA \\ *correspondence to John M. Torkelson (email: j-torkelson@northwestern.edu)
}

\begin{abstract}
A polyurethane/polyhydroxyurethane (PU/PHU) hybrid polymer was synthesized by reaction of a cyclic-carbonate-terminated prepolymer with triethylenetetramine without employing isocyanates in the final curing step. This cured elastomer contains traditional urethane linkages from the initial prepolymer reaction as well as hydroxyurethane linkages from the final chain extension reaction. The PU/PHU hybrid exhibits microphase separation as made apparent by the presence of two glass transitions and elastomeric properties with Young's modulus of 37 MPa and strain at break of $350 \%$. Most importantly, the PU/PHU hybrid polymer exhibits adhesion to polyimide, poly(vinyl chloride) (PVC), and aluminum substrates that is similar to or enhanced relative to those of polyurethane controls and literature values for typical polyurethane adhesives. In particular, the PU/PHU hybrid has T-peel forces of 7.8, 10.5, and $3.4 \mathrm{~N} / \mathrm{mm}$ on polyimide, $\mathrm{PVC}$, and aluminum, respectively, and undergoes predominately adhesive failure rather than cohesive failure. The application of this material as a model consumer-applied adhesive for potential replacement of isocyanate-based polyurethanes is also briefly discussed.
\end{abstract}

Keywords: polyurethane (A), polyhydroxyurethane, hybrid polymer, adhesion, elastomer 


\section{Introduction}

Polyurethanes (PUs) accounted for $5 \%$ of the global polymer market in $2013 ; 18$ million tons of PU are estimated to be produced in 2016 [1,2]. Polyurethanes are typically synthesized from reactions between isocyanates and alcohols. These reactions are often rapid at ambient conditions [3], which allows many PU materials to be field applied by end-use consumers. On the other hand, isocyanates can cause irritation to the eyes, nose and throat and allergic reactions (sensitization) of the lungs and skin [4-6]. Overexposure caused by atomization or heating of isocyanates has been associated with occupational asthma [5]. Engineering controls, use of personal protective equipment, and sound workplace practices enable people to work safely with isocyanates. However, a recent increase in regulatory activity associated with isocyanates [7-10] has created a need to develop chemistries that can reduce or replace isocyanate-based reactions.

Cyclic carbonates are a promising reactant for producing PU-type materials without the use of isocyanates. Multifunctional cyclic carbonate monomers or prepolymers can react with multifunctional amine monomers or prepolymers to produce polyhydroxyurethane (PHU) [2,1119]; PHUs have received significant attention for their potential as PU replacements. Relative to urethane linkages, hydroxyurethane linkages have some advantages. The hydroxyurethane linkage, which has a secondary or primary alcohol group adjacent to the traditional urethane linkage, allows for hydrogen bonding between carbonyl and hydroxyl groups, thus protecting the urethane linkage from hydrolysis [2]. Relative to PUs, PHUs also tend to exhibit increased chemical resistance, lower permeability, and better thermal stability due to the lack of biuret and allophanate linkages, and lack of porosity because there is no side reaction with water to cause gas formation [12]. However, unlike the typically rapid reaction of isocyanates with alcohols at ambient conditions, the reaction of cyclic carbonates with amines is usually slow at ambient conditions [15]; catalysis has the potential to overcome this issue $[18,20,21]$.

Among the many applications of PUs include use as elastomers and as adhesives. These applications are enabled or aided by microphase separation and hydrogen bonding between urethane linkages. In some cases adhesion is aided by hydrogen bonding between urethane 
linkages and functional groups on the substrate. To the best of our knowledge, no research has been published in the refereed literature on the production of PU analogs that serve as elastomers or adhesives and that employ cyclic carbonate reactions with amines [22].

Here, we describe the first study to produce PU analogs for use as adhesives in which the reaction of cyclic carbonates with amines plays a key role. In particular, we have designed a hybrid polymer that combines the adhesive properties of traditional PUs with the known and possible benefits of PHUs. As designed, the only reaction that would occur during application by an end-use consumer and subsequent curing would be that of cyclic carbonates with amines; thus, isocyanates would not be present during transport, storage, application or cure of the components used to make the final adhesive. By retaining urethane linkages in the resulting hybrid polymer, we not only retain the known effects of hydrogen bonding $[23,24]$ but also the known abilities of PU to physically adsorb to many substrates via van der Waals interactions and to effectively permeate grooves and pores on substrate surfaces. In addition to the relative advantages of hydroxyurethane linkages over urethane linkages that were described above, hydroxyurethane linkages possess a hydroxyl group which may further enhance adhesion via hydrogen bonding to substrate surfaces that contain appropriate atoms or functional groups.

As designed here, our hybrid PU/PHU polymer is synthesized with a final step involving reaction of a cyclic-carbonate-terminated prepolymer with triethylenetetramine (TETA). The urethane linkages in the hybrid are present in the prepolymer, and the hydroxyurethane linkages are produced in the final curing step from the reaction of cyclic carbonates with amines. We characterize the adhesive properties of the novel PU/PHU hybrid polymer via T-peel strength tests and demonstrate that the hybrid exhibits enhanced adhesion to several substrates as compared to PU controls and literature values for comparable PU adhesives.

\section{Experimental}

\subsection{Materials}

Tolylene-2,4-diisocyanate (TDI; SigmaAldrich, $95 \%$ ) and triethylenetetramine (TETA; 
SigmaAldrich, $97 \%$ ) were used as received. Voranol 220-056, a $2000 \mathrm{~g} \mathrm{~mol}^{-1}$ polypropylene glycol polyol (The Dow Chemical Company), was heated to $110^{\circ} \mathrm{C}$ in an oil bath under a dry $\mathrm{N}_{2}$ purge for $12 \mathrm{hr}$ to remove residual water. 1,4-Butanediol (SigmaAldrich, $99 \%$ ), glycerol 1,2carbonate (TCI America, 90 \%), glycerol (SigmaAldrich, $99 \%$ ) and dibutyltin dilaurate (SigmaAldrich, $95 \%$ ) were placed on active $0.4 \mathrm{~nm}$ molecular sieves for $12 \mathrm{hr}$ prior to use in order to remove residual water and prevent absorption of atmospheric moisture. Poly(vinyl chloride) (PVC; Tom Thumb Hobby, Midwest Products, Clear 0.38 mm x 193 mm x 279 mm) and polyimide (Kapton Source, $0.125 \mathrm{~mm}$ thickness) substrates were used as received. Aluminum substrates (Tom Thumb Hobby, K\&S Precision Metals, Aluminum Sheet \#255) were ultrasonicated in acetone for $1.5 \mathrm{~min}$ and then immersed in boiling deionized water for $30 \mathrm{~s}$ to rehydrate the surface. The aluminum substrates were treated less than $30 \mathrm{~min}$ prior to adhesive application.

\subsection{Synthesis of PU and PU/PHU Prepolymers}

Materials were synthesized using the prepolymer procedure in Scheme 1. Traditional PU prepolymer was synthesized by reacting excess TDI with dried polyol in a 3-neck round-bottom flask equipped with overhead stirring, a $\mathrm{N}_{2}$ inlet, and an addition funnel. The polyol (200 g, 0.1 mol) was cooled below $80^{\circ} \mathrm{C}$ while under a $\mathrm{N}_{2}$ purge before being added dropwise to TDI (63.8 $\mathrm{g}, 0.366 \mathrm{~mol}$ ) from an addition funnel. The mixture was stirred at room temperature for at least 30 min after polyol addition. Dibutyltin dilaurate was added to the mixture at a loading of 0.05 wt $\%(0.1319 \mathrm{~g}, 0.124 \mathrm{~mL})$, and the flask was placed into an oil bath at $80^{\circ} \mathrm{C}$ for $2 \mathrm{hr}$.

The procedure described above was also followed to prepare the PU/PHU prepolymer. However, after the prepolymer was stirred at $80^{\circ} \mathrm{C}$ for $2 \mathrm{hr}$, a stoichiometric amount of dry glycerol 1,2-carbonate $(62.92 \mathrm{~g}, 0.532 \mathrm{~mol})$ was added. This mixture was stirred for $2 \mathrm{hr}$ at $80^{\circ} \mathrm{C}$ or until complete disappearance of the isocyanate absorbance peak at $\sim 2200 \mathrm{~cm}^{-1}$ [25]. The peak was monitored by attenuated total reflectance Fourier transform infrared (ATR-FTIR) spectroscopy using a Bruker Tensor 37 FT-IR with a diamond/ZnSe ATR attachment.

\subsection{Chain Extension of Prepolymers}


The PU prepolymers were chain extended with 1,4-butanediol or glycerol. The traditional PU prepolymer (15 g, $2.87 \times 10^{-2} \mathrm{~mol}$ isocyanate groups) was poured into FlackTek max 20 mixing cups. A $5 \%$ loss in isocyanate content was assumed due to possible reactions with atmospheric water during sample preparation and curing. Dibutyltin dilaurate at a loading of 0.05 $\mathrm{wt} \%(0.0075 \mathrm{~g}, 7 \mu \mathrm{L})$ and either $0.014 \mathrm{~mol} 1,4$-butantediol or $9.6 \times 10^{-3} \mathrm{~mol}$ glycerol were added to the prepolymer mixture and spun at $3500 \mathrm{rpm}$ for $20 \mathrm{~s}$ in a FlackTek DAC 150.1 FVZ-K speed mixer. The mixed materials were placed onto greased Kapton paper and pressed between two aluminum plates at $60^{\circ} \mathrm{C}$ and $35 \mathrm{kPa}$ for $1 \mathrm{hr} ; 1 \mathrm{~mm}$ or $2 \mathrm{~mm}$ spacers were used for pressing. Dumbbell-shaped tensile specimens were cut from the cured plaques using a Dewes-Gumbs die; rectangular pieces for dynamic mechanical analysis were similarly obtained.

The PU/PHU prepolymer (15 g, $3.025 \times 10^{-2} \mathrm{~mol}$ carbonate groups) was poured into FlackTek max 20 mixing cups and chain extended with TETA. The carbonate concentration was calculated from reagent stoichiometry; no loss of reactive groups was assumed due to the inherent low reactivity and volatility of 5-membered cyclic carbonates. Two PU/PHU hybrid materials were synthesized; the difference regarded the effective functionality assumed for the TETA chain extender. Triethylenetetramine is a linear molecule with four amine groups; a primary amine is located on each of the two chain ends and two secondary amines reside along the backbone. Primary amines react with 5-membered cyclic carbonates more efficiently than internal secondary amines [26]; it was assumed that only some of the secondary amines would react. An effective amine functionality of TETA was taken to be 3.0 or 3.5 (instead of 4.0) and used when calculating the amount of chain extender to add to the prepolymer mix; the ratio of cyclic carbonate to amine functional groups in all materials was $1: 1$. For the formulation with an assumed TETA functionality of 3.0 (3.5), 0.01 (0.0086) mol of TETA was added to the prepolymer and mixed at $3500 \mathrm{rpm}$ for at least $5 \mathrm{~min}$ prior to pressing. A longer mixing time was required for PU/PHU prepolymers due to the increased viscosity of the prepolymer following reaction with glycerol 1,2-carbonate. Samples analogous to the traditional PUs were obtained.

\subsection{Preparation of Adhesive Samples}


Adhesive sample preparation was analogous to the procedure outlined above with slight modifications to the substrate setup. According to ASTM D 1876-08 standard test method for peel resistance of adhesives, samples should be peeled for at least $125 \mathrm{~mm}$ of their lengths. Thus, $305 \mathrm{~mm}$ x $152 \mathrm{~mm}$ aluminum plates were used to prepare the adhesive plaques. A polyimide, PVC or aluminum substrate was placed onto an aluminum plate, and $1 \mathrm{~mm}$ spacers were arranged onto the substrate so that a uniform material thickness could be obtained. The mixed material was poured onto the substrate, a second substrate was placed on top of the poured material followed by another aluminum plate, and the plaque was pressed at $60{ }^{\circ} \mathrm{C}$ at $35 \mathrm{kPa}$ for $1 \mathrm{hr}$. After pressing, the plaque was placed in a desiccator at room temperature and conditioned for 7 days prior to testing. Test specimens were cut from the original plaque.

\subsection{Characterization of Materials}

All synthesized materials were analyzed by ATR-FTIR using 16 scans from $600 \mathrm{~cm}^{-1}$ to $4000 \mathrm{~cm}^{-1}$; resulting spectra were used to determine reaction conversion. A Mettler Toledo differential scanning calorimeter (DSC 822e) was used for thermal analysis. Samples were tested at a heating rate of $10{ }^{\circ} \mathrm{C} \mathrm{min}^{-1}$ from $-80{ }^{\circ} \mathrm{C}$ to $200{ }^{\circ} \mathrm{C}$ without previous thermal treatment. Dynamic mechanical analysis (DMA) employed a TA Instruments RSAIII equipped with liquid $\mathrm{N}_{2}$ cooling and a 3500 gf transducer. Dynamic temperature sweep experiments were performed from $-100{ }^{\circ} \mathrm{C}$ to $200{ }^{\circ} \mathrm{C}$ at a heating rate of $3{ }^{\circ} \mathrm{C} \mathrm{min}^{-1}$, a frequency of $10 \mathrm{~Hz}$ and a strain of 0.03 $\%$. Due to network formation in the glycerol- and triethylenetetramine-cured samples, no molecular weight analysis could be done. Network formation was verified by dissolution experiments in several solvents in which materials exhibited swelling rather than dissolution.

Dumbbell-shaped tensile samples were prepared and tested according to ASTM D 1708. An MTS Sintech 20/G (100 N/250 N load cell; crosshead speed $130 \mathrm{~mm} \mathrm{~min}^{-1}$; $350 \mathrm{~Hz}$ data acquisition frequency) was used to obtain Young's modulus, tensile strength, and elongation at break values at room temperature.

Adhesive testing was done according to ASTM D 1876-08. Adhesive "sandwiches" were pulled apart at $180^{\circ}$ using an MTS Sintech 20/G (250 gf/100 N/250 N load cell; crosshead speed 
$254 \mathrm{~mm} \mathrm{~min}^{-1}$ ) tensile tester. Force was recorded as a function of peel distance. An average force for each specimen was calculated from the force measured after the initial peak for at least a 125 $\mathrm{mm}$ distance of sample and normalized by dividing by the average specimen width from measurements at three points along the sample length. (The PU/PHU-1 samples aged for 1 year and the PU/PHU-2 samples were slightly smaller and peeled for $76 \mathrm{~mm}$ of their length.) Peel forces were taken as the average of 6-15 specimens for each substrate/adhesive pair.

\section{Results and Discussion}

\subsection{Prepolymer Reaction: PU/PHU Hybrid Materials}

Our strategy was to create a model for a more benign material than a traditional urethane prepolymer for use in a consumer-applied adhesive. As mentioned above, traditional PU prepolymers contain reactive isocyanate groups which have the potential to contribute to adverse health effects to an end-use consumer and are facing increasing regulatory scrutiny. Although the original prepolymer material in our study is made with isocyanates, after the initial addition of TDI all isocyanate groups are reacted with glycerin carbonate to form the capped prepolymer. Figure 1 shows ATR-FTIR spectra for the original prepolymer (containing isocyanate), the capped prepolymer, and a cured PU/PHU hybrid polymer. The large isocyanate peak at $\sim 2200$ $\mathrm{cm}^{-1}$ in the original prepolymer disappears after $2 \mathrm{hr}$ reaction with glycerin carbonate. Thus, within experimental error no isocyanate remains in the capped prepolymer. This point is further

supported by the presence of the peak at $1800 \mathrm{~cm}^{-1}$ for the capped prepolymer which is indicative of the cyclic carbonate groups formed by reaction of isocyanate with glycerin carbonate.

In addition to demonstrating the full disappearance of isocyanates, ATR-FTIR was used to verify the completion of the cyclic carbonate/amine curing reaction in the formation of the PU/PHU hybrid polymer. The ATR-FTIR spectrum for the cured hybrid shows complete disappearance of the cyclic carbonate peak following chain extension, which indicates that the hybrid reached full conversion within error under the time scales studied, i.e., $1 \mathrm{hr}$ at $60{ }^{\circ} \mathrm{C}$ followed by 7 days at ambient conditions. Future study involving catalysis of the cyclic 
carbonate/amine reaction will be needed to achieve rapid curing at ambient conditions.

\subsection{Material Formation}

Table 1 shows the formulations for the four materials that were produced for study. All four used $2000 \mathrm{~g} \mathrm{~mol}^{-1}$ poly(propylene oxide) (PPO) as the soft segment. Two materials were PU/PHU hybrids synthesized with hard segments made from TDI/glycerol carbonate. Both PU/PHU hybrids used TETA as chain extender but with different amounts of TETA to account for a reduction in reactivity of secondary amines relative to primary amines in TETA. These materials are designated as PU/PHU-1 and PU/PHU-2. The other two materials were PU control samples made with TDI as the hard segment. One PU sample used 1,4-butanediol as chain extender (PU-BDO); 1,4-butanediol is a common chain extender for PUs [27-32] and has been employed in PU adhesion studies [33,34]. The second PU used glycerol as chain extender (PUGLY); as a trifunctional molecule, glycerol results in chemical cross-links similar to those present in the PU/PHU hybrids made with the tetrafunctional TETA chain extender. (A tetrafunctional alcohol analog to TETA is not commercially available.)

In order to maintain approximately the same level of traditional urethane linkages in the PU/PHU hybrids and the PU controls, there was a difference in the hard-segment levels of the final cured materials ( $31 \mathrm{wt} \%$ for the PU controls and $\sim 46 \mathrm{wt} \%$ for the PU/PHU hybrids). This difference occurs because there is about one hydroxyurethane linkage for every two urethane linkages in the PU/PHU hybrids. Both linkages are present in hybrid hard segments, but only urethane linkages are present in the PU controls. A previous study of adhesion of PU materials to aluminum found that T-peel strengths increased by $10-20 \%$ as hard segment content increased from 32 to $45 \mathrm{wt} \%$ [35]. Thus, if substantially larger increases in T-peel strength are observed in PU/PHU hybrids relative to PU controls, much of this difference will be attributable to the additional hydroxyurethane linkages rather than to an increase in hard segment content alone.

\subsection{Thermal Property Characterization}

Figure 2 shows the glass transition behavior of PU/PHU-1 and the two PU controls as evaluated by DSC derivative heat flow curves. Such data reveal the presence of a glass transition 
in the form of a peak as a function of temperature [36-38]. We used derivative heat flow curves rather than conventional heat flow curves because the latter often fail to exhibit clearly the glass transition of a minor phase, especially when that minor phase is present at small levels [39] or has a small change in heat capacity. Also, derivative heat flow curves allow quantification of the glass transition breadth which is related to composition heterogeneity or phase mixing $[37,38]$.

Table 2 shows that each of the three samples exhibited two glass transition regions, consistent with microphase separation. In each case, the soft-segment glass transition region is far below room temperature. The PU-BDO sample exhibits the broadest soft-segment glass transition, which indicates that the soft-segment matrices in PU-GLY and PU/PHU-1 are more compositionally homogeneous than in PU-BDO. In contrast, the glass transition breadths of the hard-segment domains in PU-BDO and PU/PHU-1 are both far above room temperature and relatively narrow $\left(\sim 20^{\circ} \mathrm{C}\right.$ in breadth) whereas the glass transition breadth of the hard-segment domain in PU-GLY is very broad $\left(\sim 80^{\circ} \mathrm{C}\right)$ and extends from below to well above room temperature. We postulate that the difference in hard-segment domain $T_{\mathrm{g}}$ breadth is due to the level of cross-linking. The PU-BDO sample does not undergo cross-linking while, as formulated, PU/PHU-1 undergoes relatively small levels of cross-linking (because of the different reactivities of primary and secondary amines in TETA). In contrast, PU-GLY (with glycerol containing three highly reactive primary alcohols) undergoes higher cross-linking levels in its hard-segment domains, which can lead to greater heterogeneity of glass transition response [40] and arrest microphase separation during synthesis and material formation.

Additional thermal characterization was done by DMA (See Figure 3). With DMA, the soft-segment matrix $T_{\mathrm{g}}$ is associated with a peak in dynamic loss modulus. As shown in Table 2, the $T_{\mathrm{g}}$ value obtained in this manner is above the range of the glass transition region defined by DSC. Similar differences in $T_{\mathrm{g}}$ characterization by DSC and DMA are common in the literature [41-43], and the differences tend to be greater in higher hard-segment content materials [41-44]. Like DSC, DMA indicates that the soft-segment matrix $T_{\mathrm{g}}$ decreases in the order PU-BDO $>$ PUGLY > PU/PHU-1. Also in accord with DSC, the loss modulus and $\tan \delta$ curves show that 
PU/PHU-1 exhibits the narrowest soft-segment glass transition region. Unlike DSC, DMA provides no quantitative results on hard-segment domain $T_{\mathrm{g}}$ because the materials deform and slip from the DMA grips upon approaching the second, higher $T_{\mathrm{g}}$ during heating.

\subsection{Mechanical Property Characterization}

Table 3 summarizes the room-temperature tensile properties of PU/PHU-1, PU/PHU-2, and the two PU control samples. As expected based on higher hard segment content, the two PU/PHU hybrids have higher values of Young's modulus and tensile strength than the PU controls. The small differences in amine concentration used in formulating the two PU/PHU hybrids result in only a small difference in Young's modulus and the same tensile strength and strain at break within error. The tensile properties for PU/PHU-1 and PU/PHU-2 fall in the range of some traditional PU elastomers [3,45]. Characteristic of elastomeric response, both PU/PHU hybrids and PU-GLY exhibit essentially full recovery after deformation (not leading to fracture).

\subsection{Adhesive Property Characterization}

Figure 4a compares the T-peel forces of PU/PHU-1, PU-BDO, and PU-GLY on each of three substrates: polyimide, poly(vinyl chloride) (PVC), and aluminum. With polyimide, PU/PHU-1 has a T-peel force of $\sim 7.7 \mathrm{~N} / \mathrm{mm}, \sim 60 \%$ higher than that of PU-BDO and about a factor of 40 greater than that of PU-GLY, which exhibited poor adhesion on all three substrates. The differences in adhesive properties between PU/PHU-1 and PU-BDO are much greater than those that have been attributed in the literature to hard segment content alone (in the range of $\sim 30-45 \mathrm{wt} \%$ hard segment) in conventional PU materials [35]. Thus, we do not attribute the increase in T-peel force on polyimide of PU/PHU-1 relative to that of PU-BDO to differences in hard segment content (see Table 1) but rather to the hydroxyl groups in the hydroxyurethane linkages in PU/PHU-1. The hydroxyl groups provide another avenue for hydrogen bonding with oxygen and nitrogen atoms in the polyimide repeat units and thus for enhanced adhesion.

The PU/PHU-1 sample exhibits an even greater T-peel force on PVC, $\sim 10.5 \mathrm{~N} / \mathrm{mm}$ and about $\sim 22 \%$ higher than the value exhibited by PU-BDO. This increase in T-peel force is roughly in accord with that demonstrated by Nakamae et al. [35] with an increase in hard- 
segment content from 32 to $45 \%$ in PU elastomers. We note that there is no atom or group in PVC with which hydroxyl groups in PU/PHU hybrids can hydrogen bond. Thus, the $\sim 22 \%$ increase in T-peel force on PVC exhibited by PU/PHU-1 relative to PU-BDO can be explained based on the effect of increasing hard segment content.

The PU/PHU-1 sample has a significantly smaller T-peel force on aluminum, $\sim 3.5$ $\mathrm{N} / \mathrm{mm}$. Although the average T-peel force on aluminum is $\sim 60 \%$ greater for PU/PHU-1 than for PU-BDO, the large error bars on the peel force value for PU-BDO indicate that the two values are similar within error.

Of equal or greater importance is the fact the T-peel force values exhibited by PU/PHU-1 on PVC and aluminum are better than those for some traditional PU adhesives reported in the literature. Sanchez-Adsuar synthesized several traditional PUs and reported T-peel forces on PVC ranging from 3 to $7 \mathrm{~N} / \mathrm{mm}$ [46]. (T-peel forces of PU on PVC reported in the literature range from 1 to less than $10 \mathrm{~N} / \mathrm{mm}$ [46-50], while some commercial PU adhesives range from 10 to $20 \mathrm{~N} / \mathrm{mm}[51,52]$.) Nakamae et al. [35] studied the effect of hard segment content on the adhesion of a traditional PU on aluminum. For a PU with hard segment content similar to that of our PU/PHU-1 sample, they reported a T-peel strength of $\sim 2.7 \mathrm{~N} / \mathrm{mm}$ [35]. (T-peel forces of PU on aluminum reported in the literature range from 1 to less than $6 \mathrm{~N} / \mathrm{mm}[35,53]$, while some commercial PU adhesives range from 1 to less than $13 \mathrm{~N} / \mathrm{mm}$ [51,52].) Thus, T-peel forces associated with PU/PHU-1 on PVC and on aluminum fall within the range of or exceed values in the literature for traditional PU adhesives.

In addition to the major differences in peel strength shown in Figure 4a, there were also differences in the mechanism of adhesive failure: PU/PHU-1 undergoes adhesive failure on both PVC and polyimide substrates and a mixture of adhesive and cohesive failure on aluminum, while both control PU samples undergo cohesive failure on the three substrates. Besides substrate failure, the preferred method of failure for adhesive samples is adhesive failure or adhesive split $[23,24]$, where failure occurs within the adhesive material and material remains adhered to each of the two substrates used in the test. Cohesive failure occurs when the adhesive 
peels completely away from the substrate, thus breaking interfacial bonding.

Figure $4 \mathrm{~b}$ compares T-peel forces of PU/PHU-1 and PU/PHU-2 on polyimide and PVC as functions of the amine concentration used in hybrid synthesis. (see Table 1). With both substrates, the T-peel forces for PU/PHU-1 and PU/PHU-2 samples are equal within error. Thus, a small difference in reactant concentration has little or no effect on the adhesion of the hybrids. This result is important for consumer-based applications where there is some likelihood of variance in how reactants are mixed and applied in creating the final adhesive.

Figure $4 \mathrm{~b}$ also shows the effect of aging in a laboratory (not humidity-controlled) environment on the adhesion of PU/PHU-1 to a polyimide substrate. The PU/PHU-1 sample retains about three-quarters of its original peel force after 1 year of aging. Comparison with Figure 4a shows that even after aging, the PU/PHU-1 adhesive peel force equals or exceeds those of the unaged PU control samples. While this result is promising, we note that PU adhesives aged in moist environments exhibit adhesive properties that vary substantially with substrate material and treatment conditions [54,55]. For example, in one aging study on the adhesion of PU to aluminum (19 days aging at $60{ }^{\circ} \mathrm{C}$, immersed in de-ionized water), $90 \%$ of the original

peel force was retained when the substrate had been treated with phosphoric acid but only $20 \%$ was retained after chromic acid treatment [53]. Further aging studies on the adhesive properties of PU/PHU hybrids are warranted.

\section{Summary and Outlook}

Novel PU/PHU hybrid polymers were synthesized using a final curing step involving reaction between triethylenetetramine and a prepolymer with cyclic carbonate groups on the chain ends. As prepared, the cured hybrids contain about one hydroxyurethane linkage to every two urethane linkages. The hybrids exhibit two $\mathrm{T}_{\mathrm{g}} \mathrm{s}$ resulting from microphase separation and elastomeric properties resulting from both physical and chemical cross-linking. The PU/PHU hybrids exhibit adhesion to several substrates that is better than the adhesion of PU controls made in this study and similar to or better than the adhesion of typical PU adhesives reported in 
the literature. In the case of substrates made from polyimide, which contains oxygen and nitrogen atoms that are amenable to hydrogen bonding, much of the enhancement in adhesion exhibited by the PU/PHU hybrid relative to PU controls with similar concentrations of urethane linkages can be attributed to the additional hydrogen bonding afforded by the hydroxyl groups present in the hydroxyurethane linkages. By eliminating the presence of isocyanates prior to the final curing step, these PU/PHU hybrids serve as model materials for potential replacement of consumer-applied PU adhesives that employ isocyanates in the final curing step.

Although the PU/PHU hybrids synthesized here exhibit good adhesion, the uncatalyzed reaction of cyclic carbonates with amines is slow at ambient conditions, so future study is warranted to catalytically enhance reaction rates. As the hybrids synthesized here did not vary in hard-segment content, future work should address the effect of hard segment content on hybrid adhesion. While the single long-term aging study performed here resulted in good retention of adhesion by the PU/PHU hybrid, further studies that consider ranges of aging conditions and PU/PHU hybrid composition are warranted. Given that the results of hybrid adhesion to polyimide indicate a substantial advantage of hydroxyurethane linkages relative to urethane linkages in cases where adhesion is aided by hydrogen bonding, it will be important for future work to compare the adhesion of PHUs (without urethane linkages) to the adhesion of analogous PUs. Finally, as no literature study has yet reported on thermoplastic PHU elastomers, future work is needed to delineate the similarities and differences between thermoplastic PU elastomers and thermoplastic PHU elastomers. Studies of selected issues are underway in our laboratory.

\section{Acknowledgments}

This research was supported by the University Partnership between Northwestern University and The Dow Chemical Company. This work made use of central facilities supported by the MRSEC program of the National Science Foundation (DMR-1121262) at the Northwestern University Materials Research Science and Engineering Center as well as facilities supported by Northwestern University at the Integrated Molecular Structure Education and Research Center. We also gratefully acknowledge support in the form of a SMART Fellowship (to E.K.L.). 


\section{References}

[1] Figovsky O, Shapovalov L, Leykin A, Birukova O, Patashnikova R. Progress in elaboration of nonisocyanate polyurethanes based on cyclic carbonates. Int Lett Chem Phys Astron 2012;3:52-66.

[2] Nohra B, Candy L, Blanco J-F, Guerin C, Raoul Y, Mouloungui Z. From petrochemical polyurethanes to biobased polyhydroxyurethanes. Macromolecules 2013;46:3771-3792.

[3] Awater A, Dieterich D, Goyert W, Grigat E, Hahn W, Kraft K-J. Chemical and physicalchemical principles of polyurethane chemistry and solid polyurethane materials. In: Oertel G, editor. Polyurethane Handbook. New York (NY): Hanser Publishers; 1985. p. 7-24 and p. $371-418$.

[4] Rosenstock L, Cullen M, Brodkin CA, Redlich C. Textbook of clinical occupational and environmental medicine. 2nd ed. Philadelphia: Elsevier Saunders; 2005.

[5] Tarlo SM, Liss GM. Diisocyanate-induced asthma: diagnosis, prognosis, and effects of medical surveillance measures. Appl Occup Environ Hyg 2002;17:902-8.

[6] Ott MG, Diller WF. Respiratory effects of toluene diisocyanate in the workplace: a discussion of exposure-response relationships. Crit Rev Toxicol 2003;33:1-51.

[7] Occupational Safety and Health Administration [Internet]. OSHA announces new national emphasis program for occupational exposure to isocyanates. Washington: OSHA Office of communications; 2013 [cited 2014 Sep 1]. Available from:

https://www.osha.gov/pls/oshaweb/owadisp.show document?p table=NEWS RELEASES\&p_i $\mathrm{d}=24273$.

[8] U.S. Environmental Protection Agency [Internet]. Methylene diphenyl diisocyanate (MDI) and related compounds action plan. U.S. environmental protection agency; 2011 [cited 2014 Sep 1] Available from:

http://www.epa.gov/oppt/existingchemicals/pubs/actionplans/mdi.pdf.

[9] U.S. Environmental Protection Agency [Internet]. Toluene diisocyanate and related compounds action plan. U.S. environmental protection agency; 2011 [cited 2014 Sep 1] 
Available from: http://www.epa.gov/oppt/existingchemicals/pubs/actionplans/tdi.pdf.

[10] Commision Regulation (EC) No 552/2009. Official Journal of the European Union. 2009;L164:7-31. [cited 2014 Sep 1] Available from: http://eur-

lex.europa.eu/LexUriServ/LexUriServ.do?uri=OJ:L:2009:164:0007:0031:en:PDF.

[11] Kathalewar MS, Joshi PB, Sabnis AS, Malshe VC. Non-isocyanate polyurethanes: from chemistry to applications. RSC Adv 2013;3:4110-29.

[12] Guan J, Song Y, Lin Y, Yin X, Zuo M, Zhao Y, et al. Progress in study of non-isocyanate polyurethane. Ind Eng Chem Res 2011;50:6517-27.

[13] Helou M, Carpentier JF, Guillaume SM. Poly(carbonate-urethane): an isocyanate-free procedure from a, $\omega$-di(cyclic carbonate) telechelic poly(trimethylene carbonate)s. Green Chem 2011;13:266-71.

[14] Annunziata L, Diallo AK, Fouguay S, Michaud G, Simon F, Brusson JM, et al. $\alpha, \omega-$ $\mathrm{Di}$ (glycerol carbonate) telechelic polyesters and polyolefins as precursors to polyhydroxyurethanes: an isocyanate-free approach. Green Chem 2014;16:1947-56.

[15] Tomita H, Sanda F, Endo T. Reactivity comparison of five- and six-membered cyclic carbonates with amines: basic evaluation for synthesis of poly(hydroxyurethane). J Polym Sci Part A: Polym Chem 2001;39:162-8.

[16] Steblyanko A, Choi W, Sanda F, Endo T. Addition of five-membered cyclic carbonate with amine and its application to polymer synthesis. J Polym Sci Part A: Polym Chem 2000;38:2375-80.

[17] Kihara N, Endo T. Synthesis and properties of poly(hydroxyurethane)s. J Polym Sci Part A: Polym Chem 1993;31:2765-73.

[18] Ochiai B, Inoue S, Endo T. Salt effect on polyaddition of bifunctional cyclic carbonate and diamine. J Polym Sci Part A: Polym Chem 2005;43:6282-6.

[19] Figovsky O, Shapovalov L, Axenov O. Advanced coatings based upon non-isocyanate polyurethanes for industrial applications. Surf Coatings Int Part B Coatings Trans 2004;87:83-90. 
[20] Lambeth RH, Henderson TJ. Organocatalytic synthesis of (poly)hydroxyurethanes from cyclic carbonates and amines. Polymer 2013;54:5568-73.

[21] Lombardo VM, Dhulst EA, Leitsch EK, Wilmot N, Heath WH, Gies AP, et al. Cooperative catalysis of cyclic carbonate ring opening: application towards non-isocyanate polyurethane materials. Eur J Org Chem 2015; doi: 10.1002/ejoc.201500313.

[22] A study published in 1990 (Rokicki G, Wojciechowski C. Epoxy resin modified by aliphatic cyclic carbonates. J Appl Polym Sci 1990;41:647-659) noted that a synergistic accelerating effect was observed by adding cyclic carbonates to a reaction of epoxy with triethylenetetramine and reported peel strength values among many other properties. However, this study was focused on modifying crosslinked epoxy resins rather than on synthesis of polyhydroxyurethane.

[23] Miron J, Skeist I, Schollenberger CS. Introduction to adhesives and polyurethane- and isocyanate-based adhesives. In: Skeist I, editor. Handbook of adhesives. 3rd ed. New York (NY): Van Nostrand Reinhold; 1990. p. 3-19 and p. 359-80.

[24] Comyn J, Fay PA. History of adhesive bonding and what are adhesives and sealants and how do they work?. In: Adams RD, editor. Adhesive bonding science technology and applications. Boca Raton (FL): CRC Press; 2005. p. 3-50.

[25] UCLA Chemistry Department, Table of IR Absorptions [internet]. Los Angeles (CA): UCLA Chemistry Department. [cited 2014 Jul 25]. Available from: http://www.chem.ucla.edu/webspectra/irtable/html.

[26] Webster DC, Crain AL. Synthesis and applications of cyclic carbonate functional polymers in thermosetting coatings. Prog Org Coatings 2000;40:275-82.

[27] Seefried CG, Koleske JV, Critchfield FE. Thermoplastic urethane elastomers. I. effects of soft-segment variations. J Appl Polym Sci 1975;19:3185-91.

[28] Seefried CG, Koleske JV, Critchfield FE. Thermoplastic urethane elastomer. II. effects of variations in hard-segment concentration. J Appl Polym Sci 1975;19:2503-13.

[29] Seefried CG, Koleske JV, Critchfield FE. Thermoplastic urethane elastomer. III. Effects of 
variations in isocyanate structure. J Appl Polym Sci 1975;19:2493-2502.

[30] Schneider NS, Matton RW. Thermal transition behavior of polybutadiene containing polyurethanes. Polym Eng Sci 1979;19:1122-28.

[31] Bonart R, Morbitzer L, Hentze G. X-ray investigations concerning the physical structure of cross-linking in urethane elastomers. II. butanediol as chain extender. J Macromol Sci Part B $1969 ; 3: 337-56$.

[32] Cooper SL, Tobolsky AV. Properties of linear elastomeric polyurethanes. J Appl Polym Sci 1966;10:1837-44.

[33] Hsia HC, Ma CCM, Chen DS. Adhesion properties and phase separation behavior of glycidyl-terminated polyurethanes. Die Angew Makromol Chemie 1994;220:133-49.

[34] Agrawal RK, Drzal LT. Adhesion mechanisms of polyurethanes to glass surfaces. Part II. phase separation in polyurethanes and its effects on adhesion to glass. J Adhes Sci Technol 1995;9:1381-1400.

[35] Nakamae K, Nishino T, Asaoka S, Sudaryanto. Microphase separation and surface properties of segmented polyurethane - effect of hard segment content. Int J Adhes Adhes $1996 ; 16: 233-9$.

[36] Lodge TP, Wood ER, Haley JC. Two calorimetric glass transitions do not necessarily indicate immiscibility: the case of PEO/PMMA. J Polym Sci Part B: Polym Phys 2006;44:756-63.

[37] Kim J, Mok MM, Sandoval RW, Woo DJ, Torkelson JM. Uniquely broad glass transition temperatures of gradient copolymers relative to random and block copolymers containing repulsive comonomers. Macromolecules 2006;39:6152-60.

[38] Mok MM, Kim J, Wong CLH, Marrou SR, Woo D, Dettmer CM, et al. Glass transition breadths and composition profiles of weakly, moderately and strongly segregating gradient copolymers: experimental results and calculations from self-consistent mean-field theory. Macromolecules 2009;42:7863-76.

[39] Evans CM, Henderson KJ, Saathoff JD, Shull KR, Torkelson JM. Simultaneous 
determination of critical micelle temperature and micelle core glass transition temperature of block copolymer-solvent systems via pyrene-label fluorescence. Macromolecules 2013;46:4131-40.

[40] Hourston DJ, Schafer FU. Polyurethane/polystyrene one-shot interpenetrating polymer networks with good damping ability: transition broadening through crosslinking, internetwork grafting, and compatibilization. Polym Adv Technol 1996;7:273-80.

[41] Hsu J-M, Yang D-L, Huang S. Study on thermal transitions of toluene diisocyanate-based polyurethane elastomers with poly(tetramethylene oxide) as the soft segment by TSC/RMA, DSC and DMA thermal analyzers. J Polym Res 1999;6:67-78.

[42] van Ekeren PJ, Carton EP. Polyurethanes for potential use in transparent armour investigated using DSC and DMA. J Therm Anal Calorim 2011;105:591-8.

[43] Miller JA, Lin SB, Hwang KKS, Wu KS, Gibson PE, Cooper SL. Properties of polyetherpolyurethane block copolymers: effects of hard segment length distribution. Macromolecules $1985 ; 18: 32-44$.

[44] Szycher DM. Basic concepts in polyurethane chemistry and technology, structure-property relations in polyurethanes, and isocyanate chemistry. In: Szycher's handbook of polyurethanes. 2nd ed. Boca Raton (FL): CRC Press; 2012. p. 1-86.

[45] Baker A-MM, Margolis JM, Mead J. Thermoplastics, thermosets, and elastomeric materials and processes. In: Harper CA, editor. Handbook of plastics, elastomers, \& composites. $4^{\text {th }}$ ed. New York (NY): McGraw-Hill; 2002. p. 1-108 and p. 189-229.

[46] Sanchez-Adsuar MS. Influence of the composition on the crystallinity and adhesion properties of thermoplastic polyurethane elastomers. Int J Adhes Adhes 2000;20:291-8.

[47] Vega-Baudrit J, Navarro-Banon V, Vazquez P, Martin-Martinez JM. Addition of nanosilicas with different silanol content to thermoplastic polyurethane adhesives. Int $\mathbf{J}$ Adhes Adhes 2006;26:378-87.

[48] Kim BS, Kim BK. Enhancement of hydrolytic stability and adhesion of waterborne polyurethanes. J Appl Polym Sci 2005;97:1961-9. 
[49] Jhon Y-K, Cheong I-W, Kim J-H. Chain extension study of aqueous polyurethane dispersions. Colloid Surface A 2001;179:71-8.

[50] Aram-Ais F, Torro-Palau AM, Orgiles-Barcelo AC, Martin-Martinez, JM. Addition of rosin acid during thermoplastic polyurethane synthesis to improve its immediate adhesion to PVC. Int J Adhes Adhes 2005;25:31-8.

[51] 3M Industrial Adhesives and Tapes Division [Internet]. Scotch-Weld polyurethane reactive (PUR) easy adhesives. 3M; 2006 [cited 2014 Jun 1] Available from:

http://multimedia.3m.com/mws/media/3411910/scotch-weldtm-polyurethane-pur-easy-adhez17005-010-030-060.pdf.

[52] 3M Industrial Adhesives and Tapes Division [Internet]. Scotch-Weld polyurethane reactive adhesives. 3M; 2006 [cited 2014 Jun 1] Available from:

http://multimedia.3m.com/mws/media/3411930/scotch-weldtm-polyurethane-te031-te040ts115hgs-ts230.pdf.

[53] Brewis DM, Critchlow GW. Locus of failure of T-peel joints formed between aluminum and various adhesives. Int J Adhes Adhes 1997;17:33-8.

[54] Barron V, Buggy M, Mas A, Schue F. Durability of APC2/polyurethane adhesive joints for biomedical applications. Int J Adhes Adhes 2000;20:361-66.

[55] Ramani K, Verhoff J, Kumar G, Blank N, Rosenberg S. Environmental durability of moisture-cured urethane adhesive joints. Int J Adhes Adhes 2000;20:377-85. 


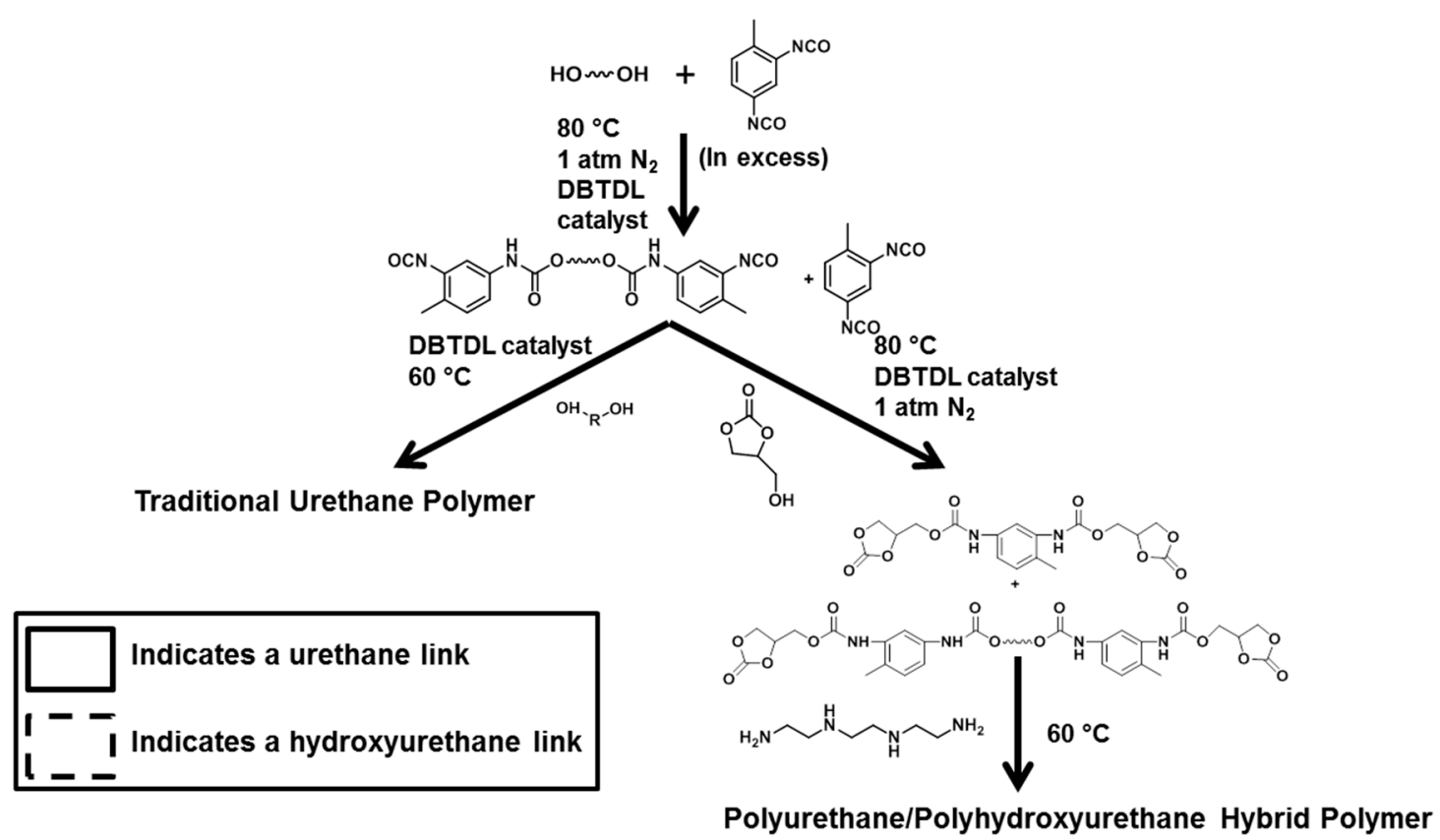

Possible Structure of Traditional Urethane Polymer

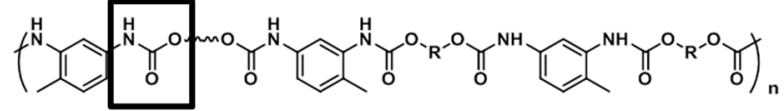

Possible Structures of Polyurethane/Polyhydroxyurethane Hybrid Polymer

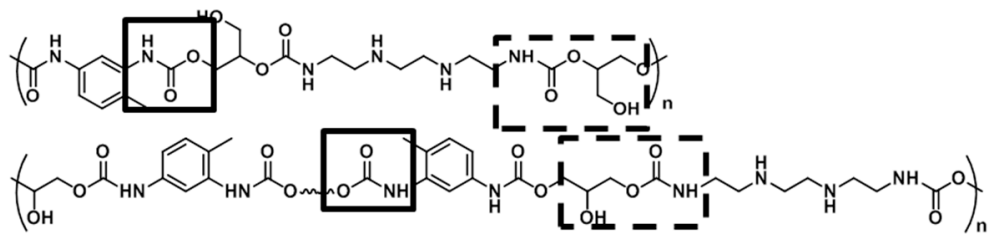

SCHEME 1 Prepolymer and chain extension reactions for the creation of polyurethane (PU) and polyurethane/polyhydroxyurethane (PU/PHU) hybrid polymers. The final material structures provided are only one set of possible structures obtained. In addition, in the PU/PHU polymer, the hydroxyurethane linkages can either possess a primary or secondary hydroxyl group adjacent to the linkage; a mixture of these products is expected. 
a)

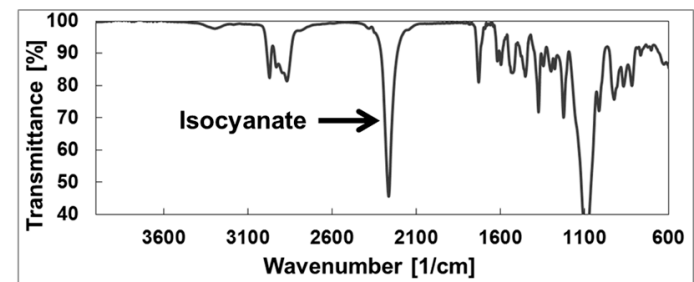

b)

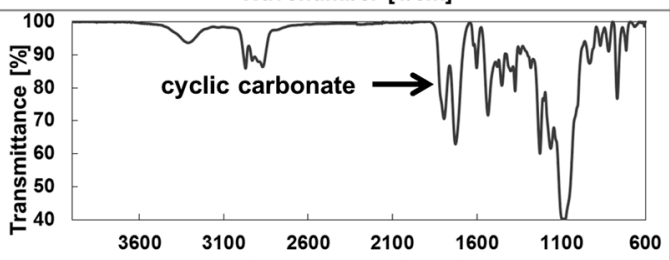

c)

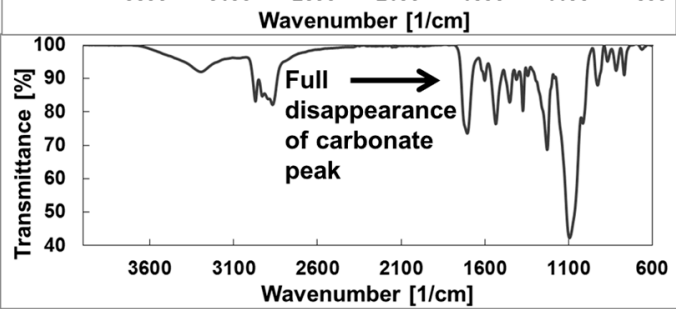

FIGURE 1 ATR-FTIR spectra from $600 \mathrm{~cm}^{-1}$ to $4000 \mathrm{~cm}^{-1}$. (a) Spectrum of the PU prepolymer which illustrates the presence of isocyanate moieties in the material. (b) Spectrum of the $\mathrm{PU} / \mathrm{PHU}$ prepolymer which illustrates the complete disappearance of isocyanate groups and the appearance of cyclic carbonate functionality. (c) Spectrum of the cured PU/PHU hybrid polymer after chain extension with TETA which illustrates the complete disappearance of cyclic carbonate functionality corresponding to $100 \%$ conversion $\left(1 \mathrm{hr}\right.$ at $60{ }^{\circ} \mathrm{C}$ followed by 7 days at ambient temperature).

TABLE 1 Material Formulations.

\begin{tabular}{ccccc}
\hline Sample Name & Soft Segment & Hard Segment & Chain Extender & Hard Segment Content (wt \%) \\
\hline PU/PHU-1 & $2000 \mathrm{~g} \mathrm{~mol}^{-1}$ PPO & TDI/glycerol carbonate & TETA (3.0) $)^{\mathrm{a}}$ & 45.8 \\
PU/PHU-2 & $2000 \mathrm{~g} \mathrm{~mol}^{-1} \mathrm{PPO}$ & TDI/glycerol carbonate & TETA (3.5) & 45.8 \\
PU-BDO & $2000 \mathrm{~g} \mathrm{~mol}^{-1}$ PPO & TDI & $1,4-$-Butanediol & 30.5 \\
PU-GLY & $2000 \mathrm{~g} \mathrm{~mol}^{-1}$ PPO & TDI & Glycerol & 30.6
\end{tabular}

${ }^{a}$ Assumed effective functionality of triethylenetetramine for reactant calculations. All reactions were completed at a ratio of cyclic carbonate:amine functional groups of 1:1. With these calculations TETA was assumed to possess either 3.0 reactive amine groups or 3.5 reactive amine groups. This decrease in effective functionality was assumed because of the inherent decrease in reactivity of secondary amines as compared to primary amines. ${ }^{b}$ Calculated from traditional hard segment wt $\%$ equation. 
(a)

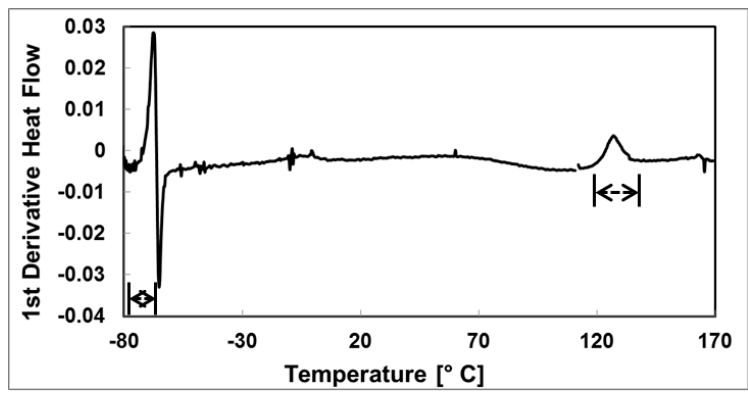

(b)

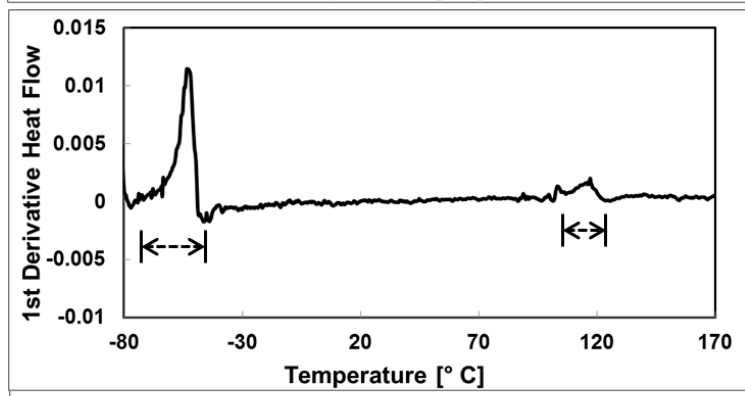

(c)

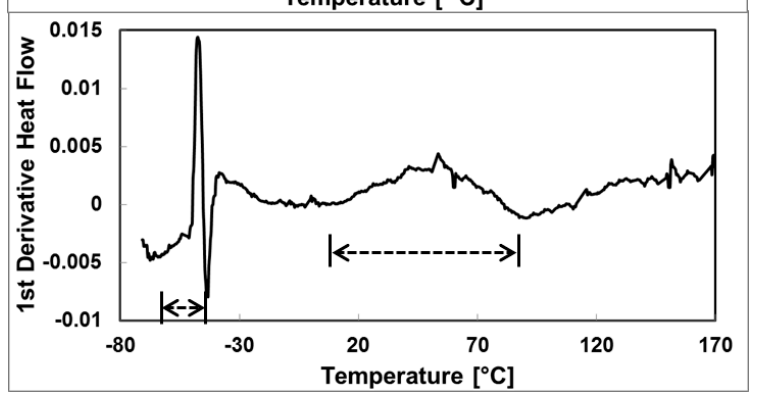

FIGURE 2 First derivative heat flow traces from DSC experiments conducted at a heating rate of $10{ }^{\circ} \mathrm{C} \mathrm{min}^{-1}$. (a) PU/PHU-1 (b) PU-BDO (c) PU-GLY. The arrows depict the breadth of each observed transition.

TABLE 2 Thermal Transitions Determined from DSC and DMA Measurements

\begin{tabular}{|c|c|c|c|c|c|}
\hline \multirow[t]{2}{*}{ Material } & \multirow[t]{2}{*}{$\begin{array}{l}\text { Test } \\
\text { Method }\end{array}$} & \multicolumn{2}{|c|}{$\begin{array}{l}\text { Soft Segment } \\
\mathrm{T}_{\mathrm{g}}\left({ }^{\circ} \mathrm{C}\right)\end{array}$} & \multicolumn{2}{|c|}{$\begin{array}{l}\text { Hard Segment } \\
\mathrm{T}_{\mathrm{g}}\left({ }^{\circ} \mathrm{C}\right)\end{array}$} \\
\hline & & $O n^{a}$ & $\mathrm{End}^{\mathrm{b}}$ & $O n^{a}$ & $\mathrm{End}^{\mathrm{b}}$ \\
\hline \multirow[t]{2}{*}{ PU/PHU-1 } & $\mathrm{DSC}^{\mathrm{c}}$ & -72 & -65 & 121 & 139 \\
\hline & DMA $^{d}$ & \multicolumn{2}{|c|}{-44} & \multicolumn{2}{|c|}{$\mathrm{n} / \mathrm{a}$} \\
\hline \multirow[t]{2}{*}{ PU-BDO } & $\mathrm{DSC}^{\mathrm{c}}$ & -61 & -46 & 105 & 126 \\
\hline & $D_{M A}{ }^{d}$ & \multicolumn{2}{|c|}{-28} & \multicolumn{2}{|c|}{$\mathrm{n} / \mathrm{a}$} \\
\hline \multirow[t]{2}{*}{ PU-GLY } & $\mathrm{DSC}^{\mathrm{c}}$ & -51 & -43 & 7 & 87 \\
\hline & DMA $^{d}$ & \multicolumn{2}{|c|}{-38} & \multicolumn{2}{|c|}{$\mathrm{n} / \mathrm{a}$} \\
\hline
\end{tabular}

\footnotetext{
${ }^{a}$ The onset of the glass transition as determined by DSC using the first derivative method. ${ }^{\mathrm{b}}$ The endset of the glass transition as determined by DSC using the first derivative method. ${ }^{\circ}$ Values were determined from DSC first derivative heat flow traces at a heating rate of $10^{\circ} \mathrm{C} \mathrm{min}{ }^{-1}$. ${ }^{d}$ The transition using DMA is obtained from the peak in the loss modulus determined in the tensile geometry at $0.03 \%$ strain, $10 \mathrm{~Hz}$ frequency, and at a heating rate of $3{ }^{\circ} \mathrm{C} \mathrm{min}{ }^{-1}$.
} 

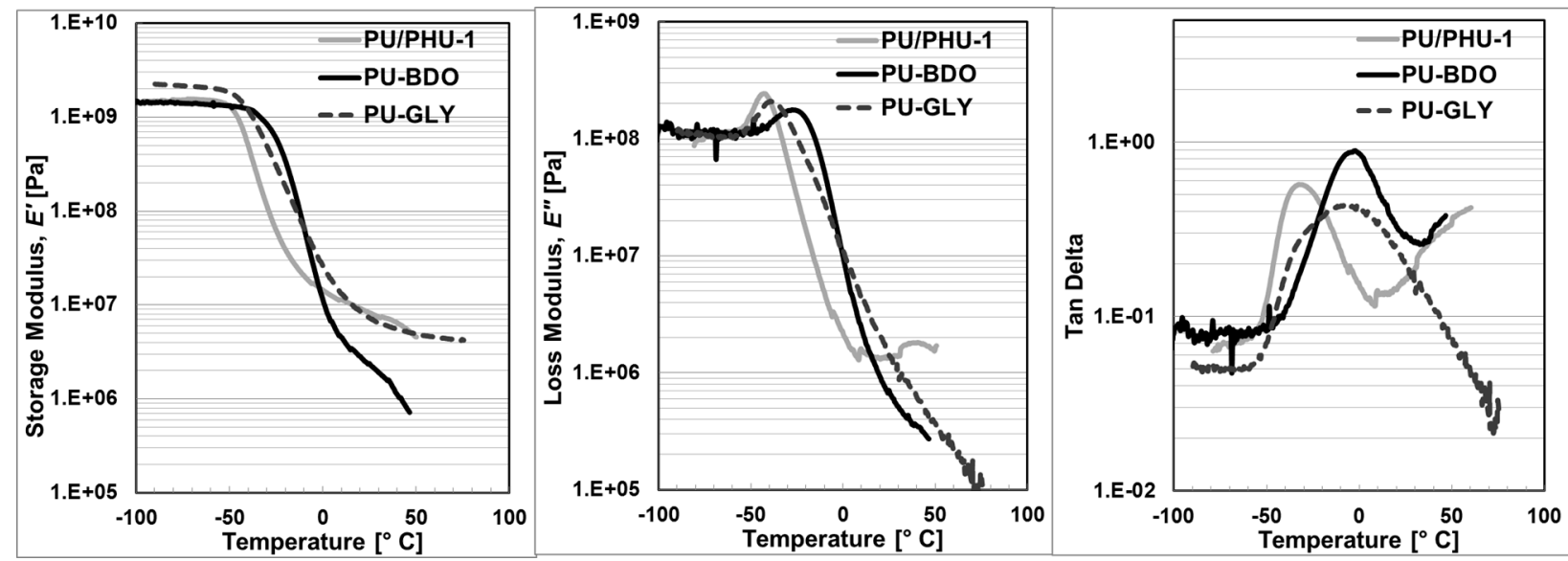

FIGURE 3 Dynamic mechanical analysis (DMA) comparisons of the tensile storage modulus (E'), tensile loss modulus (E'), and tan $\delta$ of PU-BDO, PU-GLY and PU/PHU-1. The hard-segment transition was not observed using DMA because the samples were not robust enough to survive the test at higher temperatures; the tensile samples slipped from the testing fixture at high temperature.

TABLE 3 Mechanical Properties of PU and PU/PHU Hybrid Materials ${ }^{\mathrm{a}}$

\begin{tabular}{cccc}
\hline Material & $\begin{array}{c}\text { Young's } \\
\text { Modulus } \\
(\mathrm{MPa})\end{array}$ & $\begin{array}{c}\text { Tensile } \\
\text { Strength } \\
(\mathrm{MPa})\end{array}$ & $\begin{array}{c}\text { Strain at } \\
\text { Break }(\%)\end{array}$ \\
\hline PU/PHU-1 & $37 \pm 6$ & $4.5 \pm 1.1$ & $350 \pm 100$ \\
PU/PHU-2 & $26 \pm 3$ & $3.2 \pm 0.4$ & $320 \pm 70$ \\
PU-BDO & $18 \pm 2$ & $0.8 \pm 0.1$ & $>2000$ \\
PU-GLY & $4.0 \pm 0.2$ & $2.6 \pm 0.2$ & $90 \pm 10$
\end{tabular}

${ }^{\text {a }}$ Materials were tested at ambient conditions $\left(T=23^{\circ} \mathrm{C}\right)$ using a $100 \mathrm{~N}$ load cell, a ram head speed of $130 \mathrm{~mm} \mathrm{~min}^{-1}$, and a $350 \mathrm{~Hz}$ data acquisition frequency. 


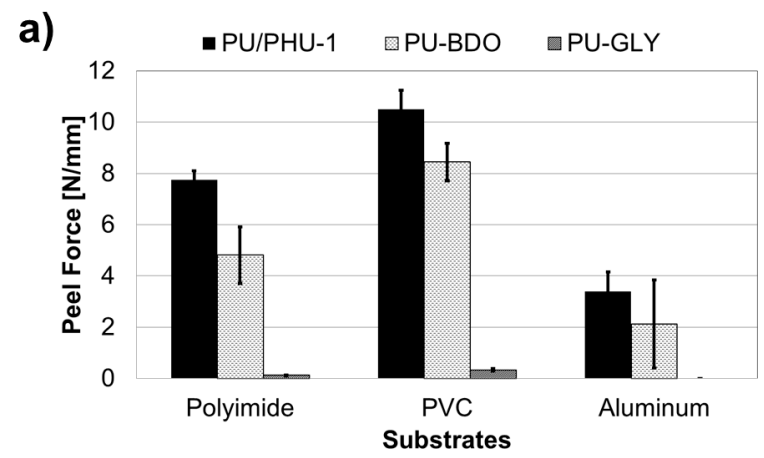

b)

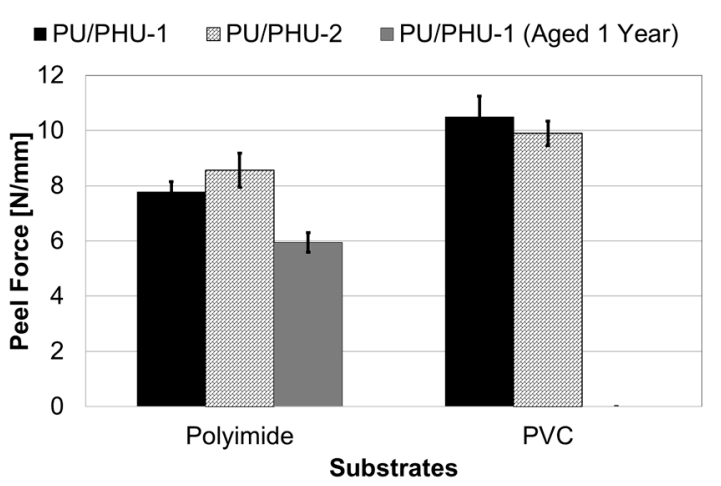

FIGURE 4 Adhesive peel forces from $180^{\circ} \mathrm{T}$-peel tests using ASTM D 1876-08. Error bars are the representative standard deviation of each sample set consisting of 6-15 samples. (a) Comparison of PU/PHU-1 T-peel strength with traditional PU controls. (b) Comparison of PU/PHU-1, PU/PHU-2, and PU/PHU-1 samples aged for 1 year. 